\title{
CASA DE TURU É PAU DE MANGUE
}

Fernando Alves da Silva Júnior (D)

Universidade Federal do Pará I Belém - PA - Brasil 
Sento-me para escrever enquanto a memória dos eventos ainda está próxima. Saímos para a Vila do Bonifácio, também conhecida como Vila dos Pescadores, na manhã do feriado de adesão do Pará ao território brasileiro. Fomos a convite de amigos. O local era um restaurante que fica ao final da Vila, próximo ao mar. Um bom período de conversas somou-se à tradicional caldeirada de pescada, que foi seguida da oportunidade de acompanhar a retirada do famoso turu, objeto deste ensaio fotográfico (Figuras 1 a 19). Chamo-o de "famoso" porque ele é muito conhecido por nome, mas difícil de se ver pessoalmente, em Bragança pelo menos é assim. Nos restaurantes da cidade, dificilmente encontramos essa iguaria para degustação.

Mal finalizo o almoço e ouço o chamado de uma das responsáveis pelo espaço: "Se queres tirar turu, o momento é esse!”. Engulo o pouco pirão escaldado que restava no prato e parto pelos fundos do restaurante que, a propósito, é uma pousada. A equipe já havia partido, uma criança de aproximadamente oito anos me guia até o local onde está seu pai, o extrator de turu conhecido na localidade como Rosinho. Vamos margeando uma entrada de mar que funde a nossa tradicional concepção de porto (de pequenas proporções) com a de praia; resta a dúvida, é um pedaço de praia, por conta da quantidade de areia, ou se trata de um porto, por conta dos barcos que ali se encontram ancorados? Eu não saberia responder. Estava mais preocupado com a areia abrasando meus pés e com o sol fervendo minha cabeça do que com uma possível definição da paisagem local. Para minha surpresa, o trajeto foi bastante curto: uns trezentos metros até encontrar o pequeno grupo de quatro pessoas. De onde os encontrei, era possível avistar uma área de mangue toda seca.

Pergunto o motivo daquele manguezal ter perdido o verde e tombado, dando às nossas vistas um espaço semelhante a uma área de queimada. Terá sido alguma ação antrópica que teria desencadeado tal atrocidade? O extrator de turu, preocupado com a má impressão que a Vila poderia passar, explica que aquele cenário era decorrente da areia que havia avançado na área do mangue. De fato, é o que logo observamos quando nos deparamos com aquela área de árvores caídas, onde, bem ao lado, um manguezal viceja com suas raízes despontando da lama. Podemos esperar que em pouco tempo aquela parte de troncos caídos logo estará semelhante a uma praia. É a dinâmica da natureza alterando o espaço. É mais cômodo se apegar a essa ideia depois de olhar para o topo das árvores e avistar ninhos do tecelão japiim confeccionados em um misto de palha e nylon de cordas de pesca. Na ausência do produto natural, tece-se com aquilo que mais se assemelha 
e abunda no entorno, produtos antrópicos. O gesto humano também é visto nos troncos ali tombados; as marcas do machado deixam à mostra diversos canais (orifícios) na madeira seca; outras incursões já se aventuraram por esses lados em busca do turu, e tiveram êxito!

A arrogância de um aventureiro inexperiente diria que era só procurar a melhor árvore tombada e lascá-la ao meio para obter o molusco. No entanto, não é por esses meios que o saber de Rosinho trabalha. O olhar cuidadoso do extrator logo diz que não é toda árvore que abriga esse molusco. Existem pequenos orifícios nos troncos que denunciam a presença de seu morador, o turu. É preciso, portanto, conhecimento para partir o madeiro certo. Após eleger o tronco/casa do turu que seja habitado/a, vem o trabalho braçal de partilo, a fim de confirmar a presença do morador. O machado rompe a primeira camada da árvore e logo a confirmação do êxito vem em forma de água. Escuta-se do extrator a frase lacônica: "Sangrou". Isso significa que a madeira escolhida tem turu, $\mathrm{e}$ muito, é importante ressaltar.

O sangue vem em forma de água. Quando se corta o madeiro em aproximadamente seis centímetros, e escorre uma água meio lamacenta e esbranquiçada, é sinal mais do que seguro da presença do turu. Os canais que ele cria na madeira são cheios de líquido, próprio para mantê-lo hidratado. Os golpes continuam até que o tronco seja partido na horizontal; a parte removida é de aproximadamente sessenta centímetros, novamente partida na vertical, momento em que a iguaria se mostra em sua inteireza: um molusco branco, cujo formato logo lembra uma minhoca albina e bem nutrida. O famoso turu é uma espécie de cupim do mangue, pois é da madeira seca que ele retira seu alimento. A propósito, com uma breve pesquisa logo encontramos referências a ele como teredo, gusano, busano ou mesmo cupim-do-mar. Com o tronco partido, ele deve ser removido com cuidado. Seu corpo é tão flexível e sensível, que um aperto mais forte pode parti-lo, o que não o inutiliza. Despreza-se a cabeça do molusco, e o corpo deve ser tratado com uma incisão vertical para remover algo que muito se assemelha à argila do mangue. Após lavado, está pronto para o consumo e, de preferência, deve ser consumido logo que é retirado do tronco, acompanhado de sal, limão e pimenta. Não tínhamos pimenta, mas o sal e o limão não faltavam.

O turu, assim como os demais animais, deve ser transformado em "coisa" para ser ingerido com mais facilidade. Quando nos alimentamos de carne bovina ou suína, por exemplo, é preciso remover tudo que existe da lembrança do animal para transformá-la em "coisa”, ou seja, em partes que apagam o animal como um ser vivo completo. 
É mais fácil comer uma costela de porco quando você não enxerga o animal em sua totalidade. Tudo o que existe dele (suas partes reconhecíveis) deve ser removido, para que seja, digamos assim, mais comestível. Algo semelhante se aplica ao turu, é mais fácil comê-lo partido que em sua inteireza.

Contudo, a forma aparentemente desagradável e indigesta logo se apaga com o gosto sutilmente adocicado do molusco, cujo paladar mais diversificado certamente o relacionará a outro molusco menos repugnante, a ostra. Turu é ostra à sua forma! Uns o degustam sem mastigar, assim não é possível a comparação, mas àqueles que gostam de sentir sabor e textura, a mastigação imprime na memória um gosto ainda mais peculiar. Engana-se quem pensa que ele seja consumido apena in natura. O caldo de turu é igualmente saboroso e, em mãos dedicadas, pode adquirir um sabor superior. Essa iguaria da região do Salgado paraense somente perdurará enquanto a presença das novas gerações (a exemplo dos dois filhos de Rosinho) assegurar que a comensalidade do turu em seu modo tradicional seja possível. 


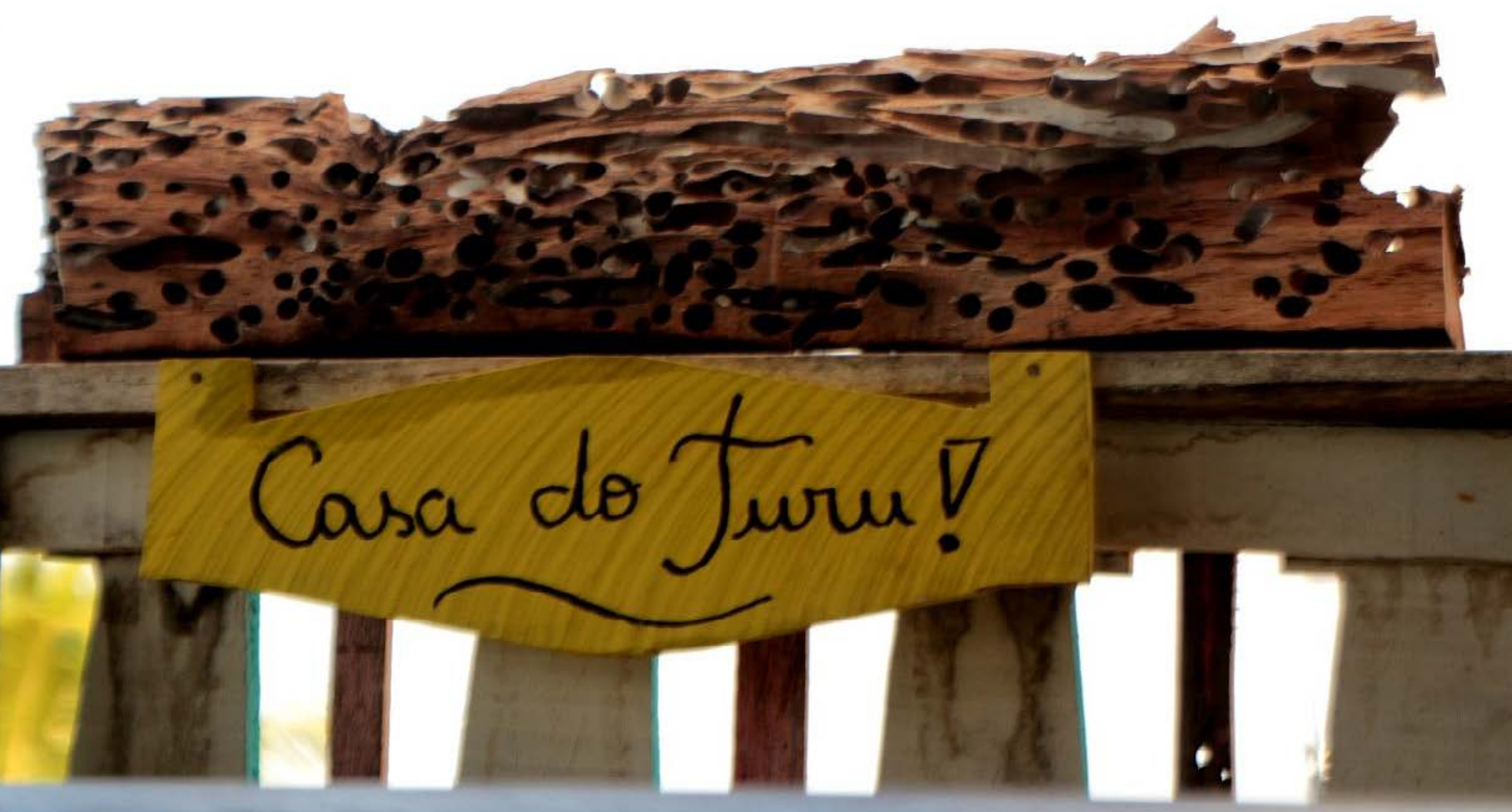

$\operatorname{mon}$

Figura 1 - Segmento de um tronco de mangue em exposição. Foto: Fernando Alves da Silva Júnior (2019). 
Figura 2 - Filho de Rosinho indo em direção ao local da retirada do turu. Foto: Fernando Alves da Silva Júnior (2019). 


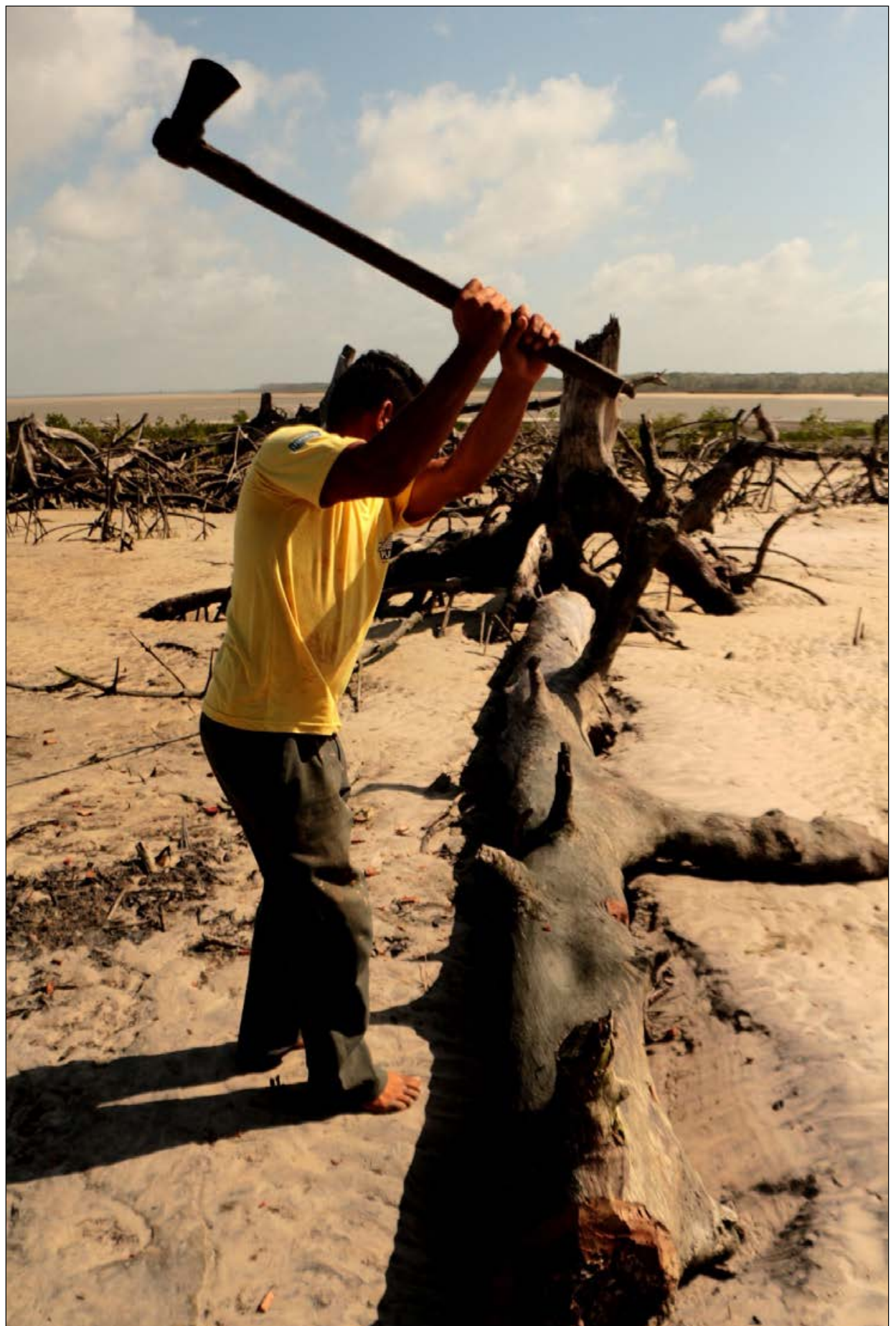

Figura 5 - Rosinho lascando o tronco. Foto: Fernando Alves da Silva Júnior (2019). 


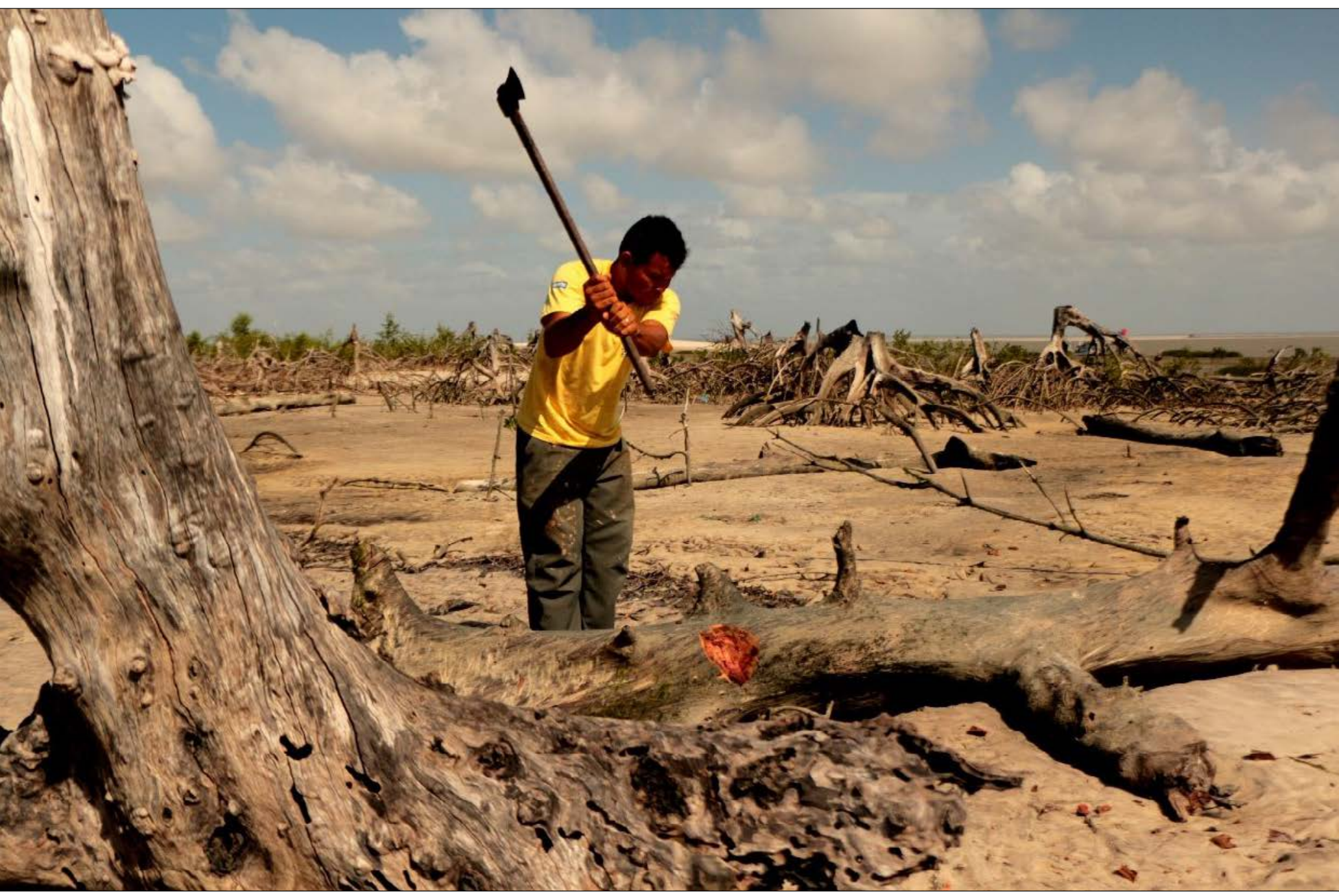

Figura 6 - A paisagem de fundo mostra uma área de mangue invadida pela areia. Foto: Fernando Alves da Silva Júnior (2019). 


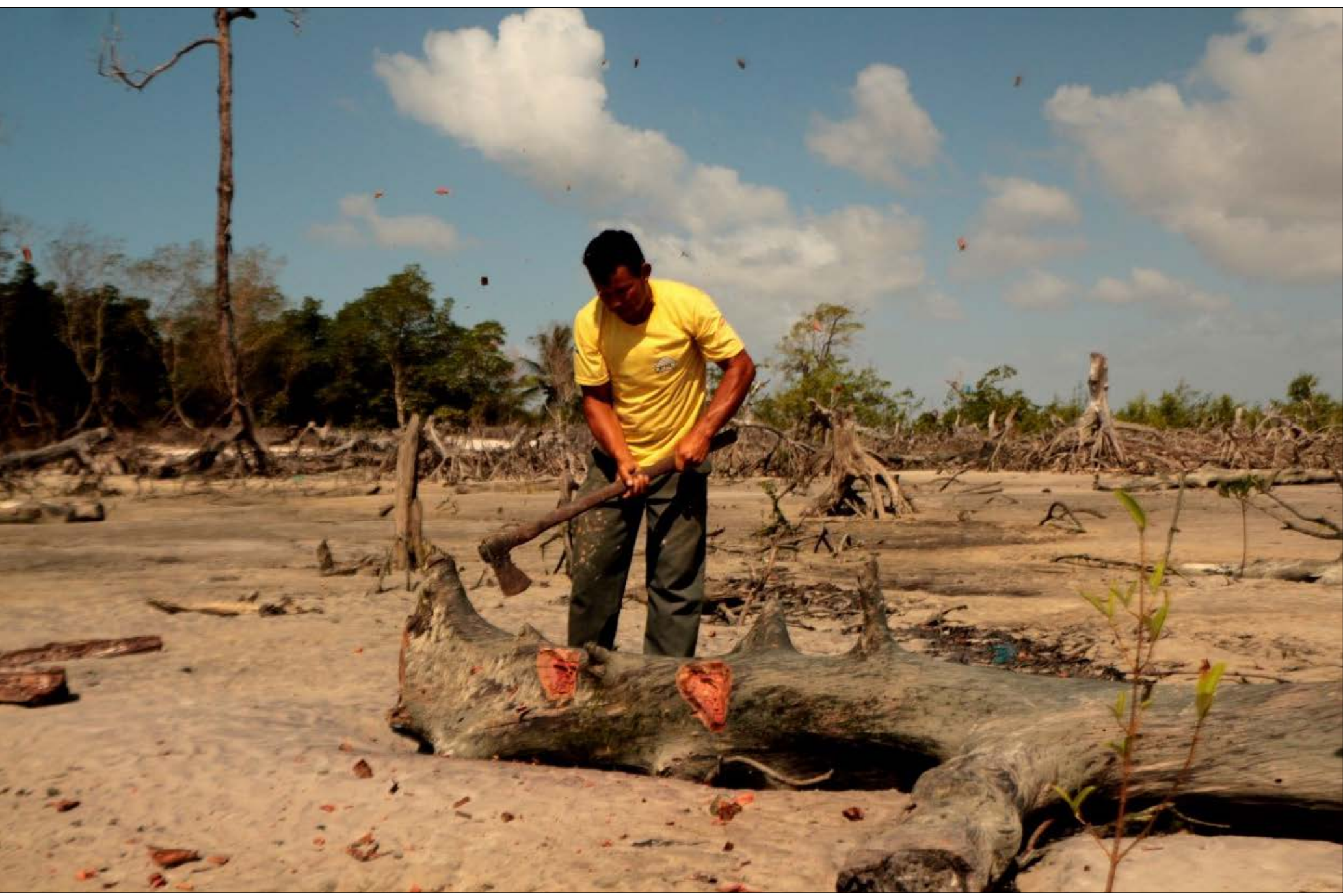

Figura 7 - Rosinho golpeia outra parte do madeiro. Foto: Fernando Alves da Silva Júnior (2019). 


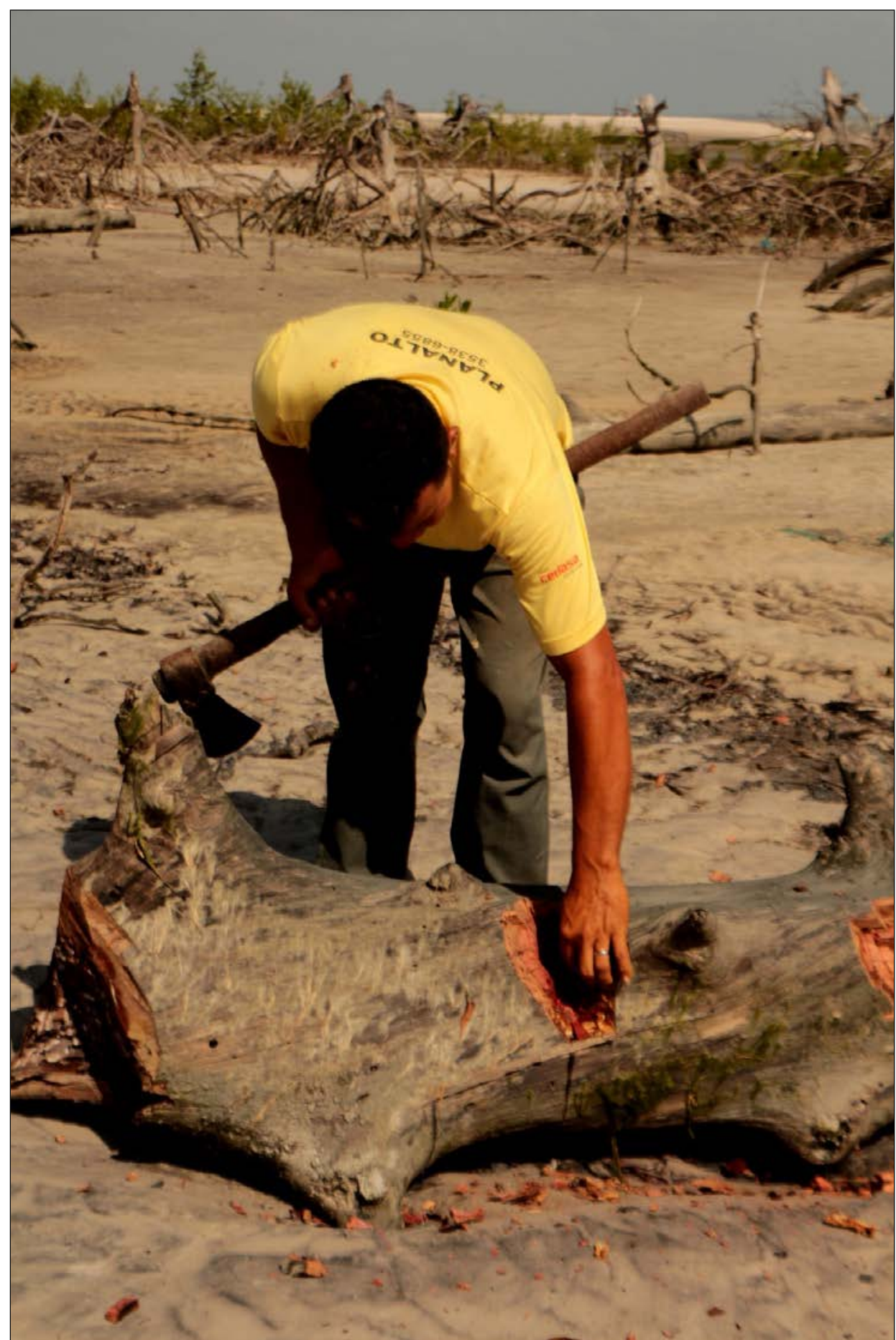

Figura 8 - Momento em que o tronco "sangra" e confirma a presença do turu. Foto: Fernando Alves da Silva Júnior (2019). 


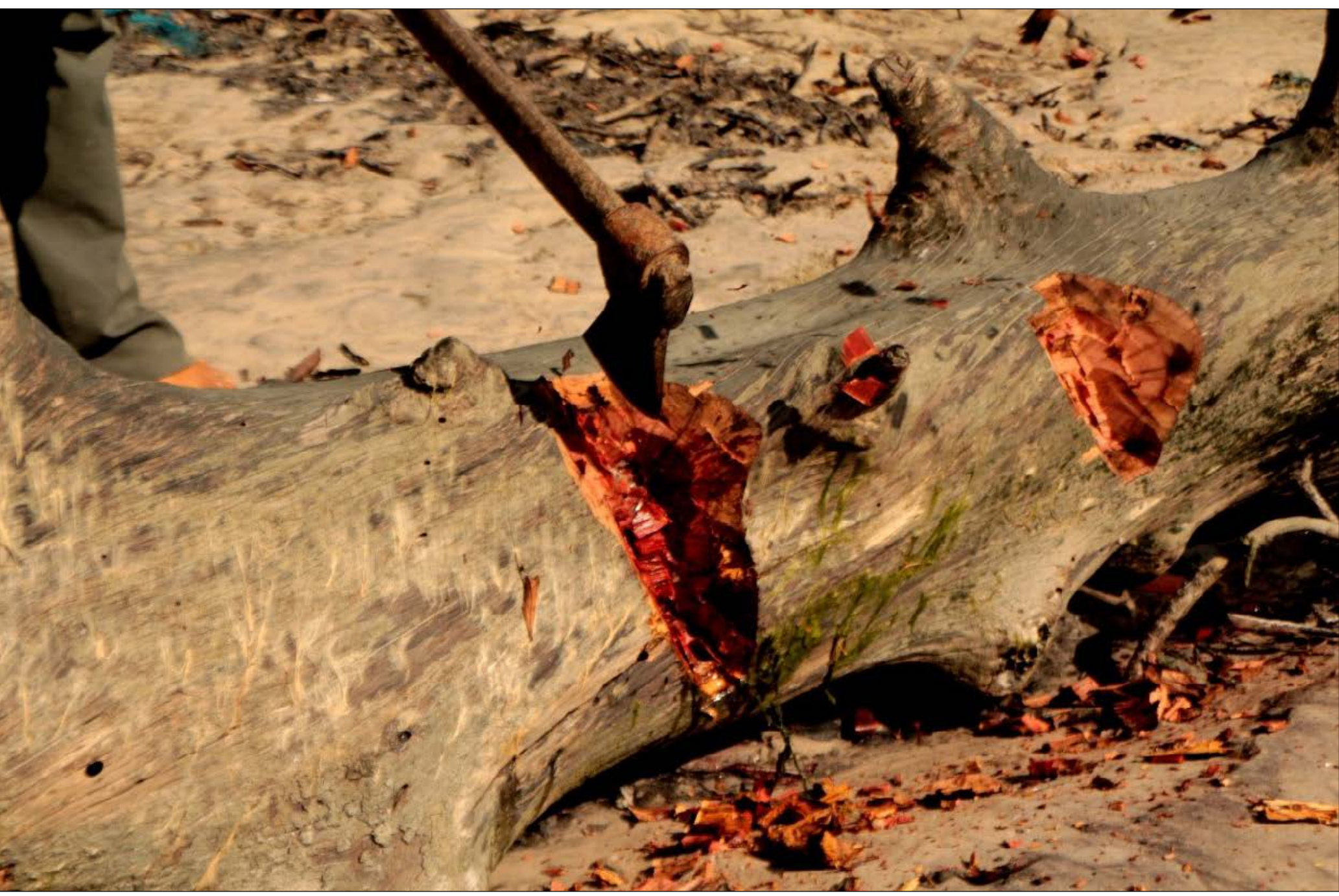

Figura 9 - Um líquido esbranquiçado próprio do turu sai do tronco. Foto: Fernando Alves da Silva Júnior (2019). 


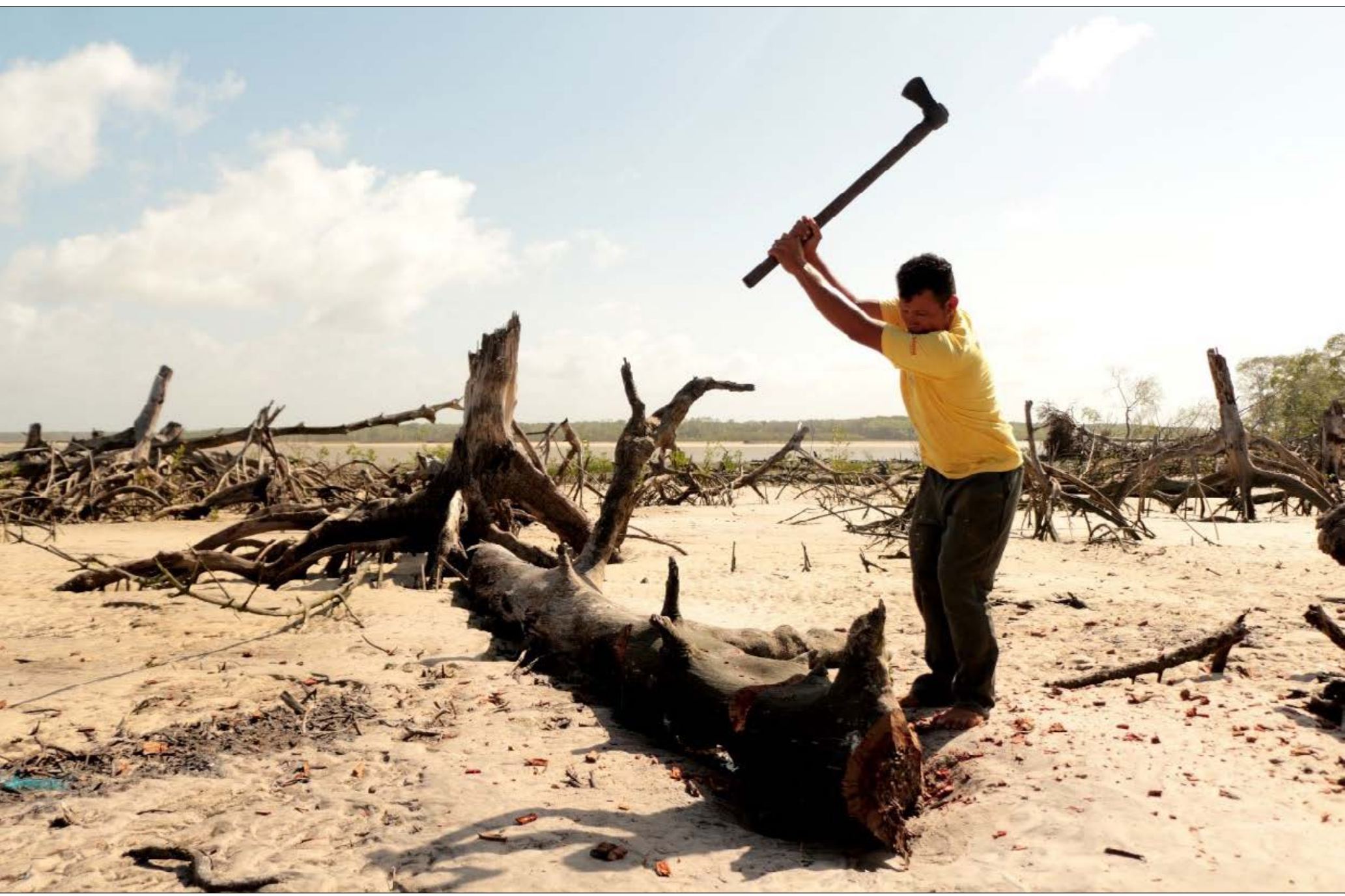

Figura 10 - O tronco aparentemente já havia sido cortado para extração do turu. Foto: Fernando Alves da Silva Júnior (2019). 


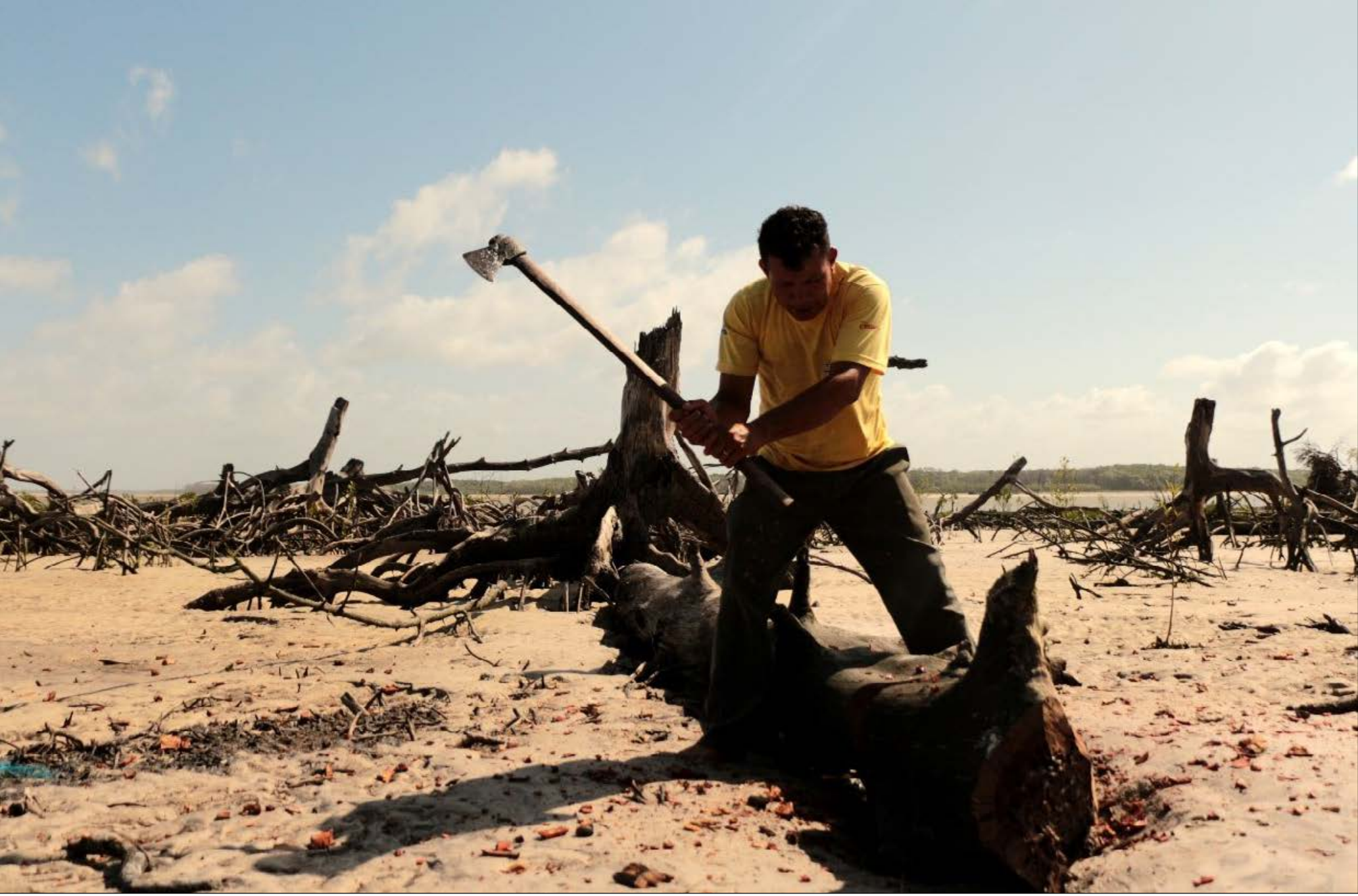

Figura 11 - Rosinho muda de posição para segmentar o madeiro. Foto: Fernando Alves da Silva Júnior (2019). 


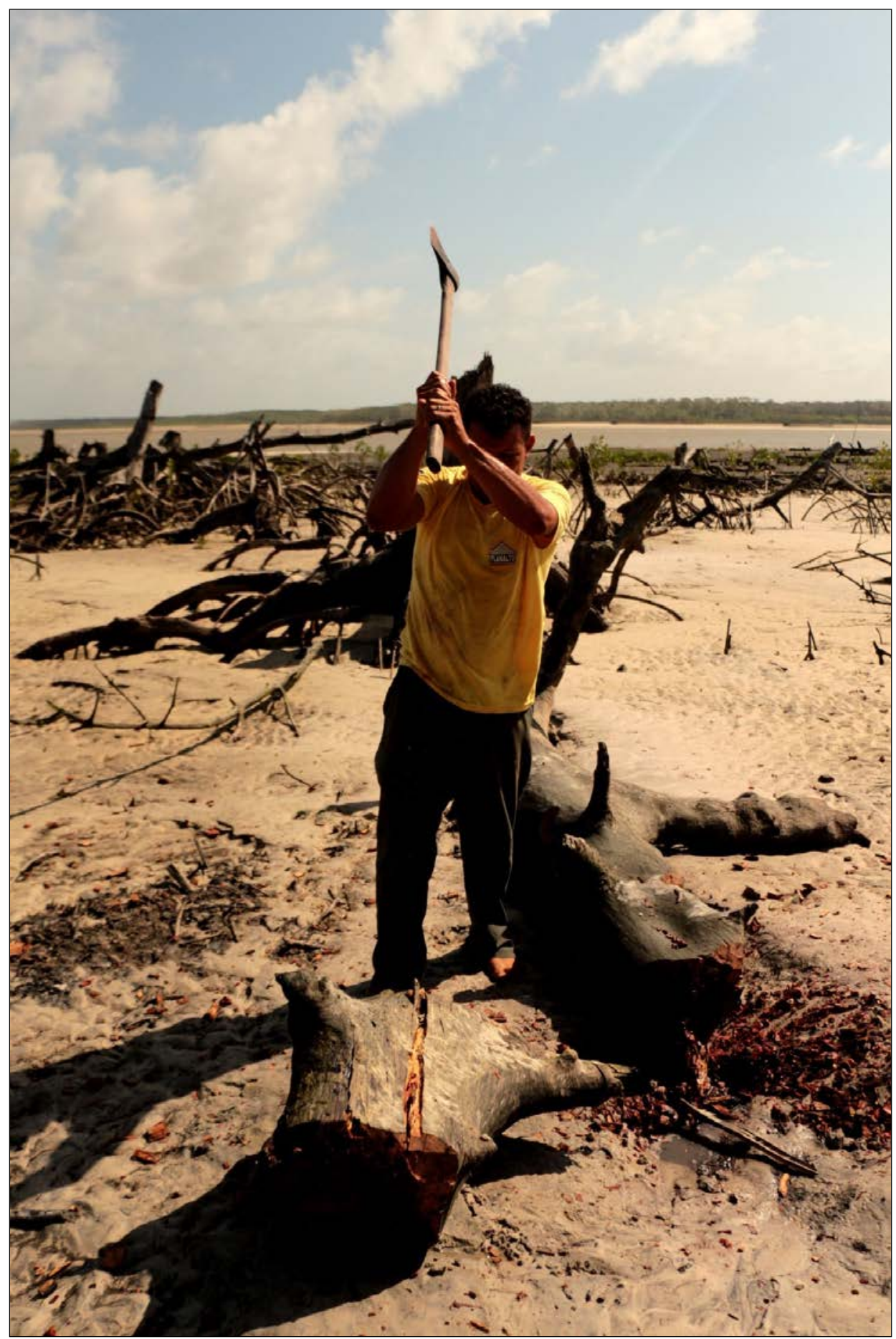

Figura 12 - Rosinho lascando o segmento de madeiro de aproximadamente $60 \mathrm{~cm}$. Foto: Fernando Alves da Silva Júnior (2019). 


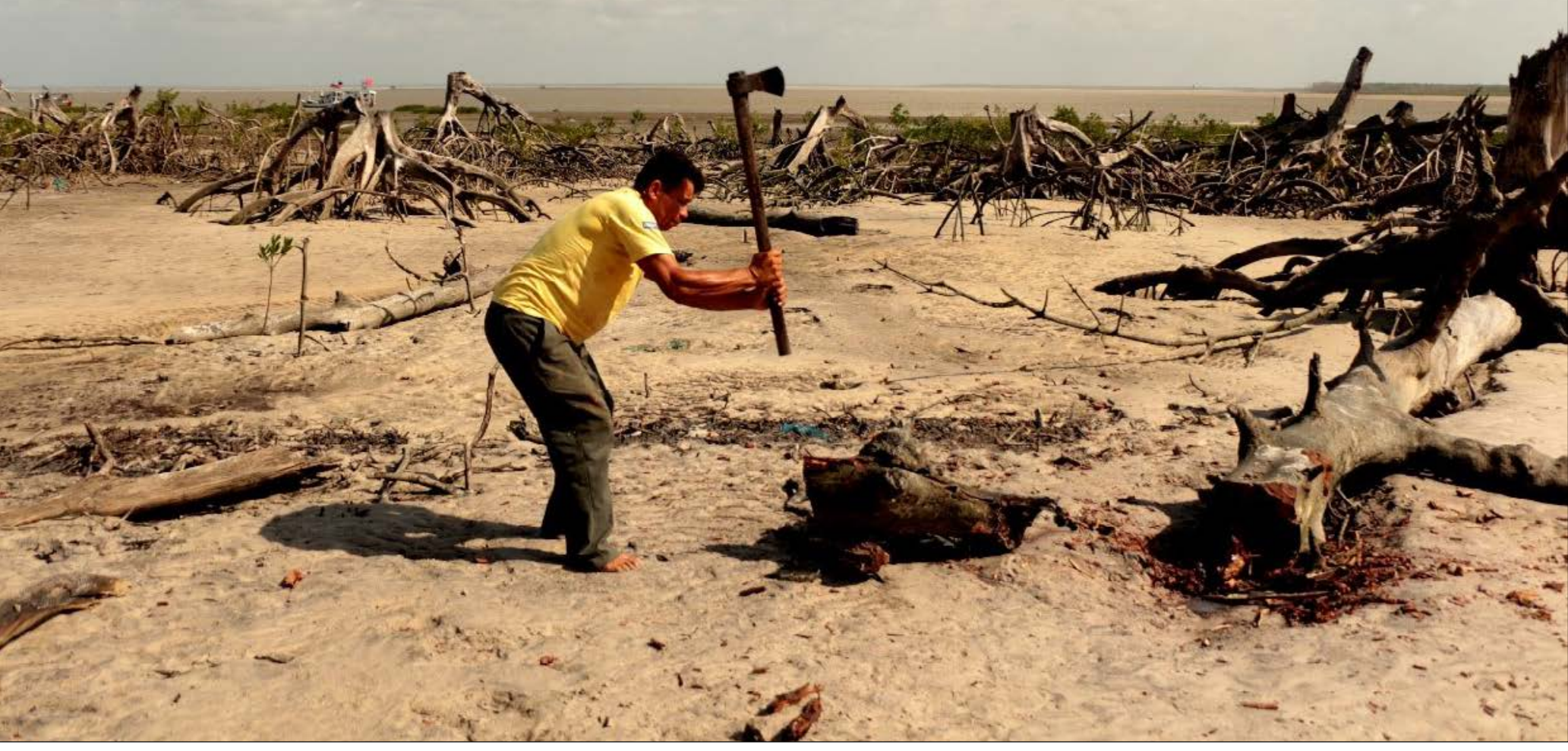

Figura 13 - Rosinho golpeando o lado oposto do tronco. Foto: Fernando Alves da Silva Júnior (2019). 


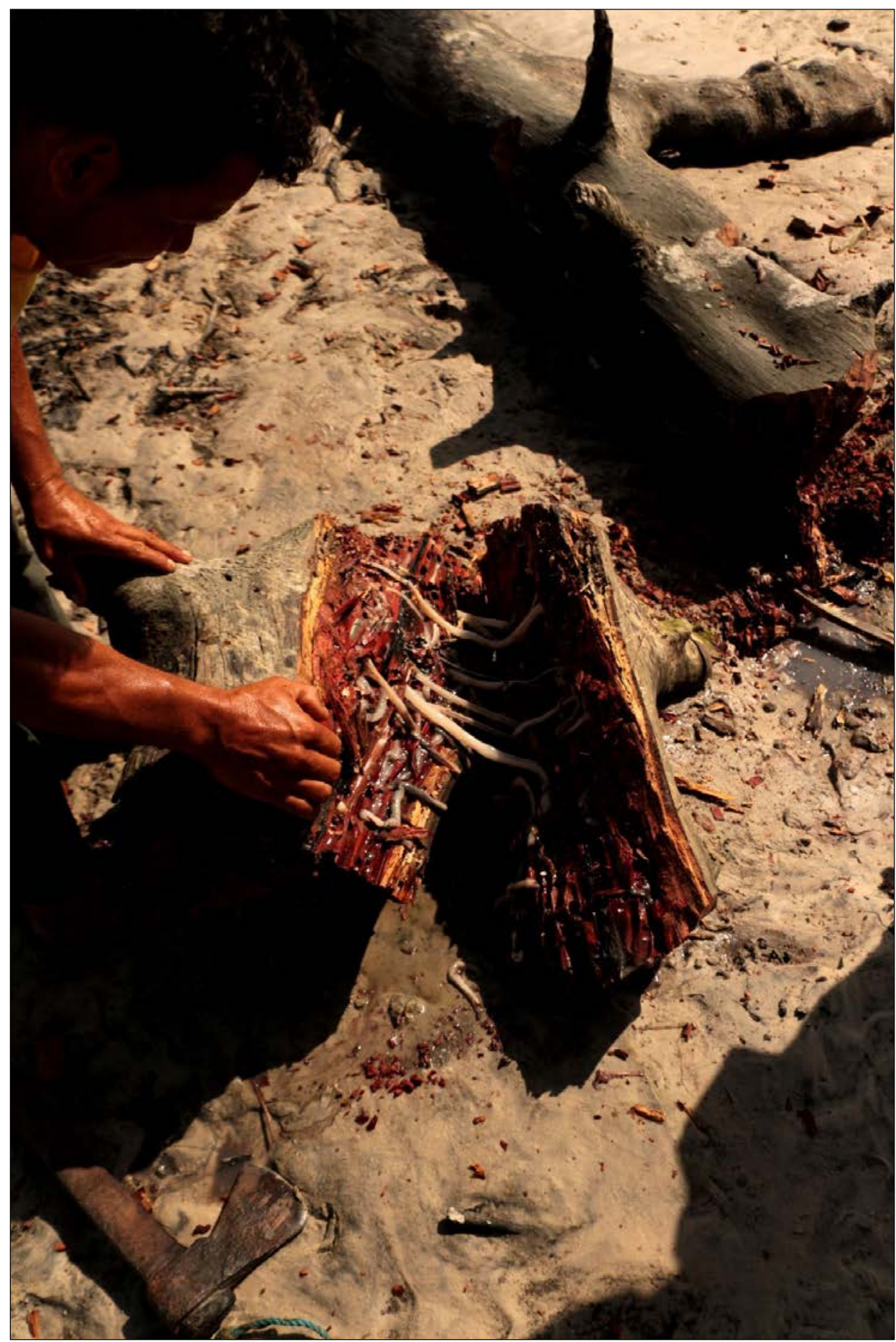

Figura 14 - Tronco verticalmente segmentado repleto de turu. Foto: Fernando Alves da Silva Júnior (2019). 


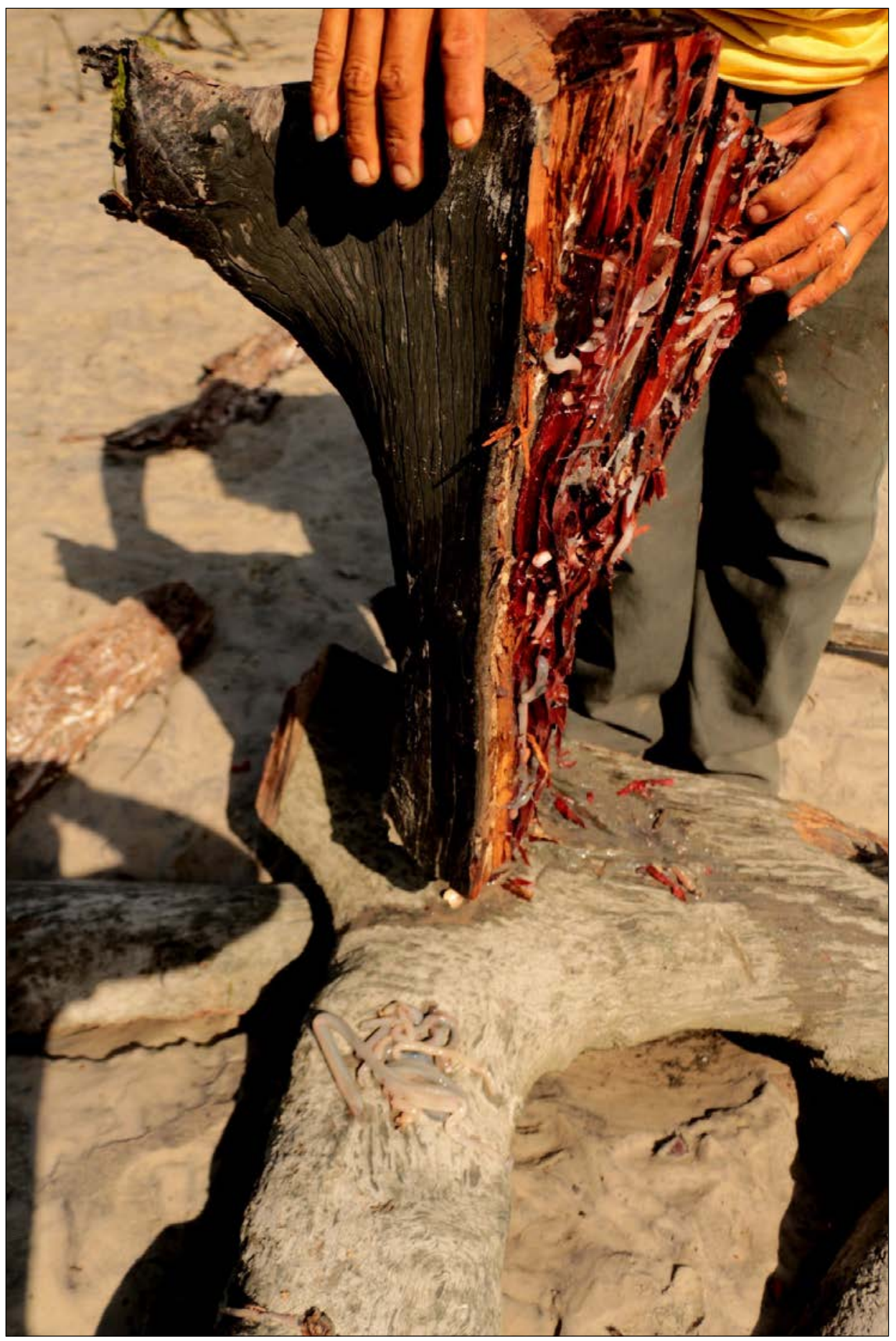

Figura 15 - Rosinho exibe o tronco com alguns turus já removidos. Foto: Fernando Alves da Silva Júnior (2019). 


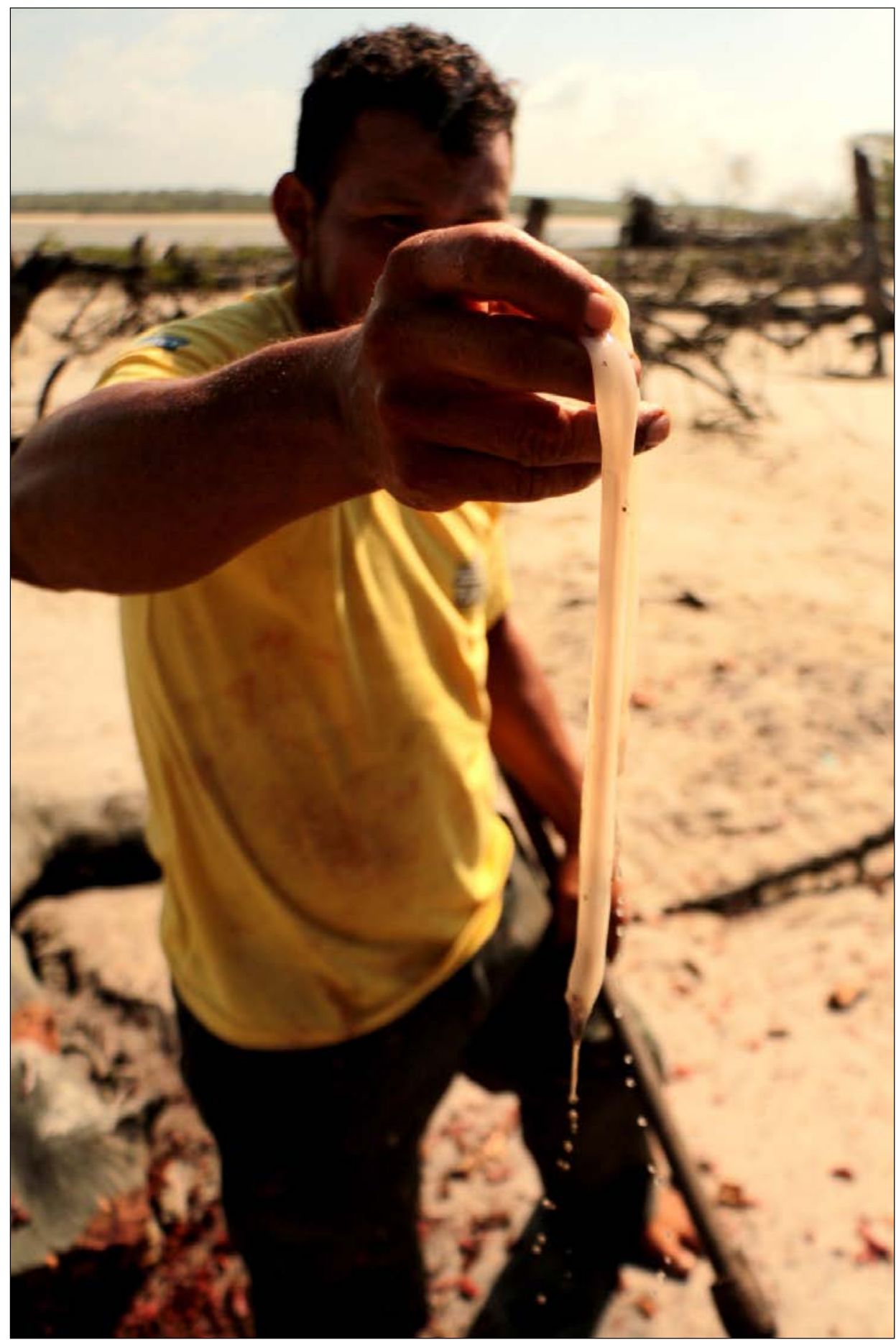

Figura 16 - Rosinho posando com um turu. Foto: Fernando Alves da Silva Júnior (2019). 


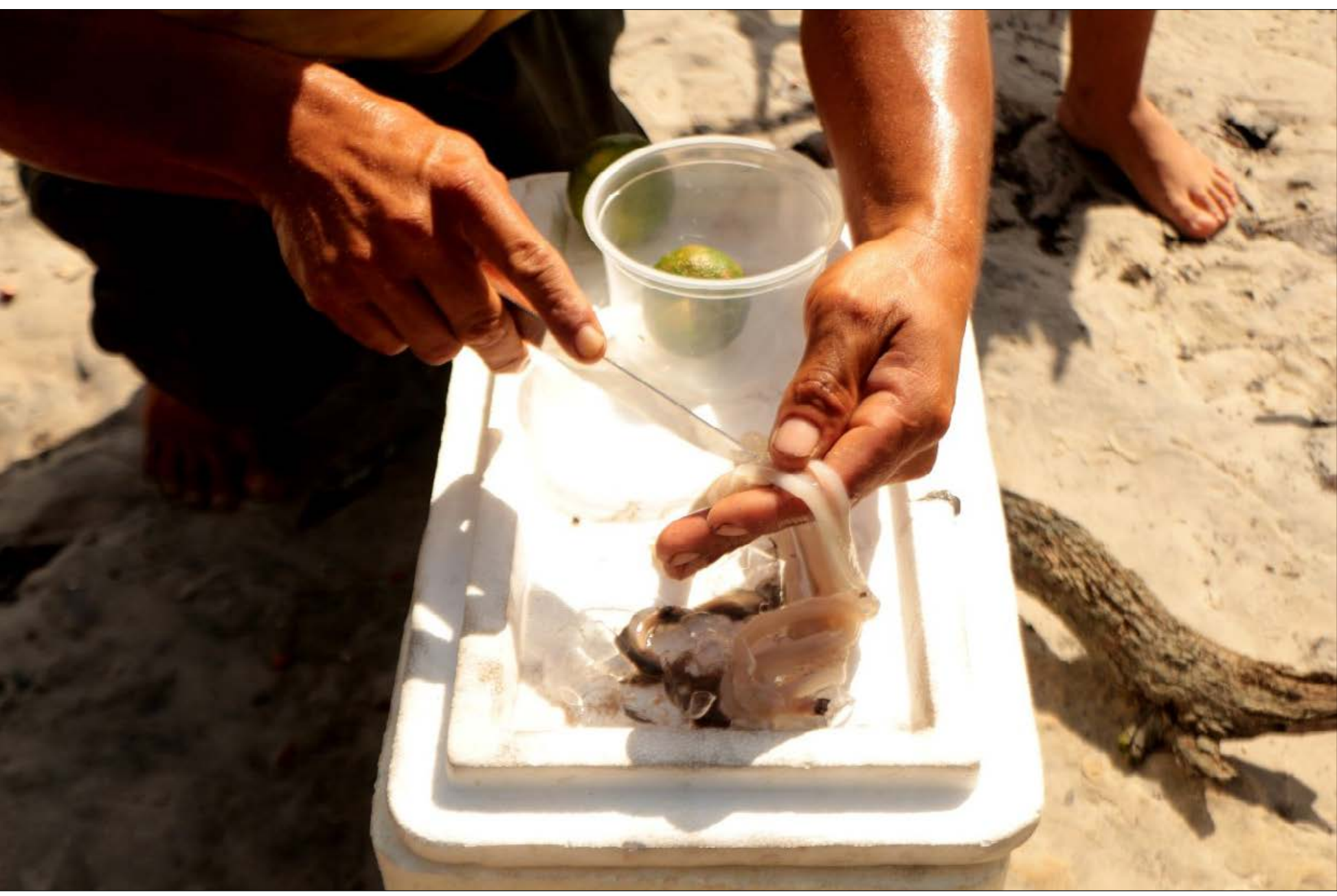

Figura 17 - Rosinho fazendo uma incisão vertical no turu. Foto: Fernando Alves da Silva Júnior (2019). 


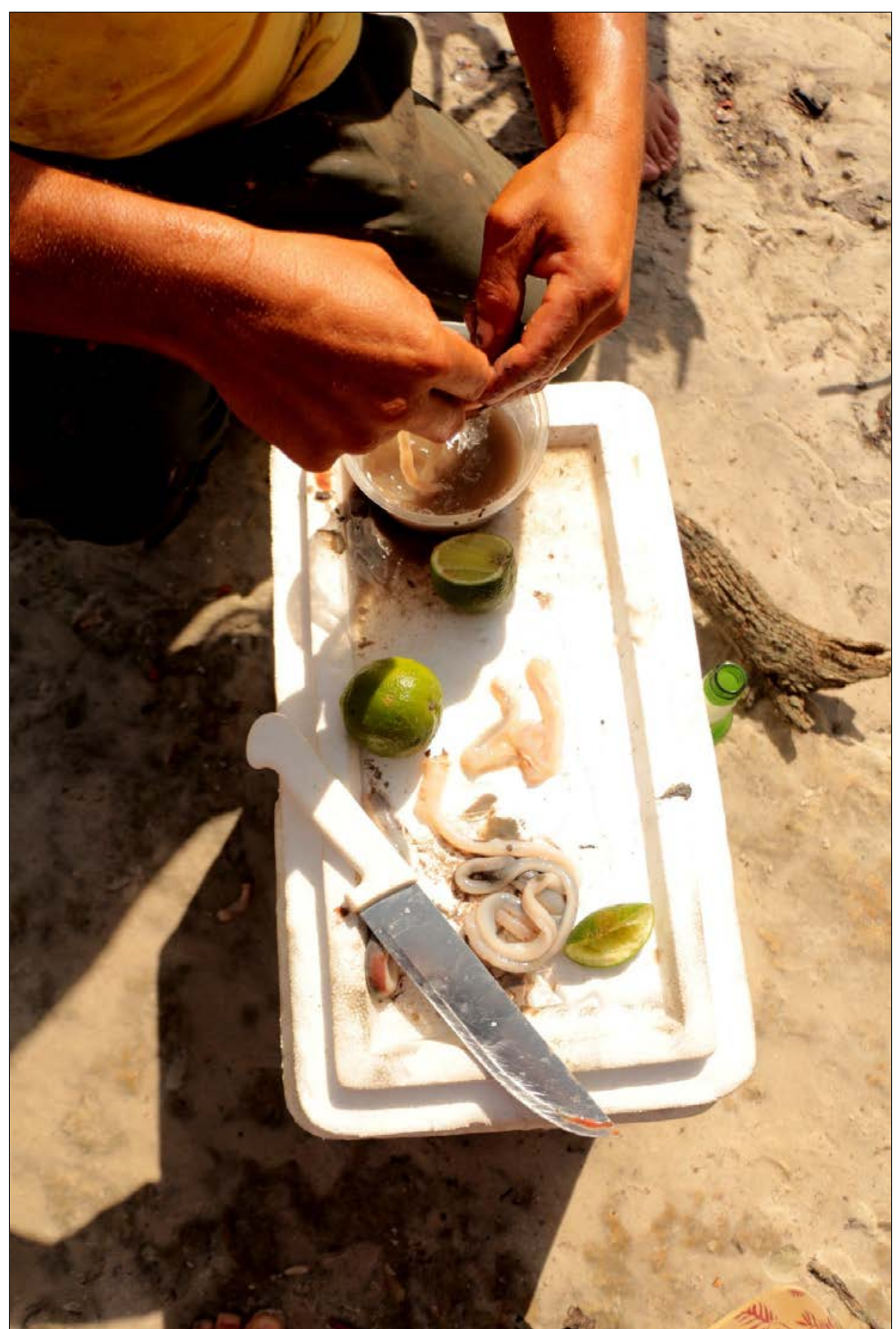

Figura 18 - Rosinho limpando o turu. Foto: Fernando Alves da Silva Júnior (2019). 


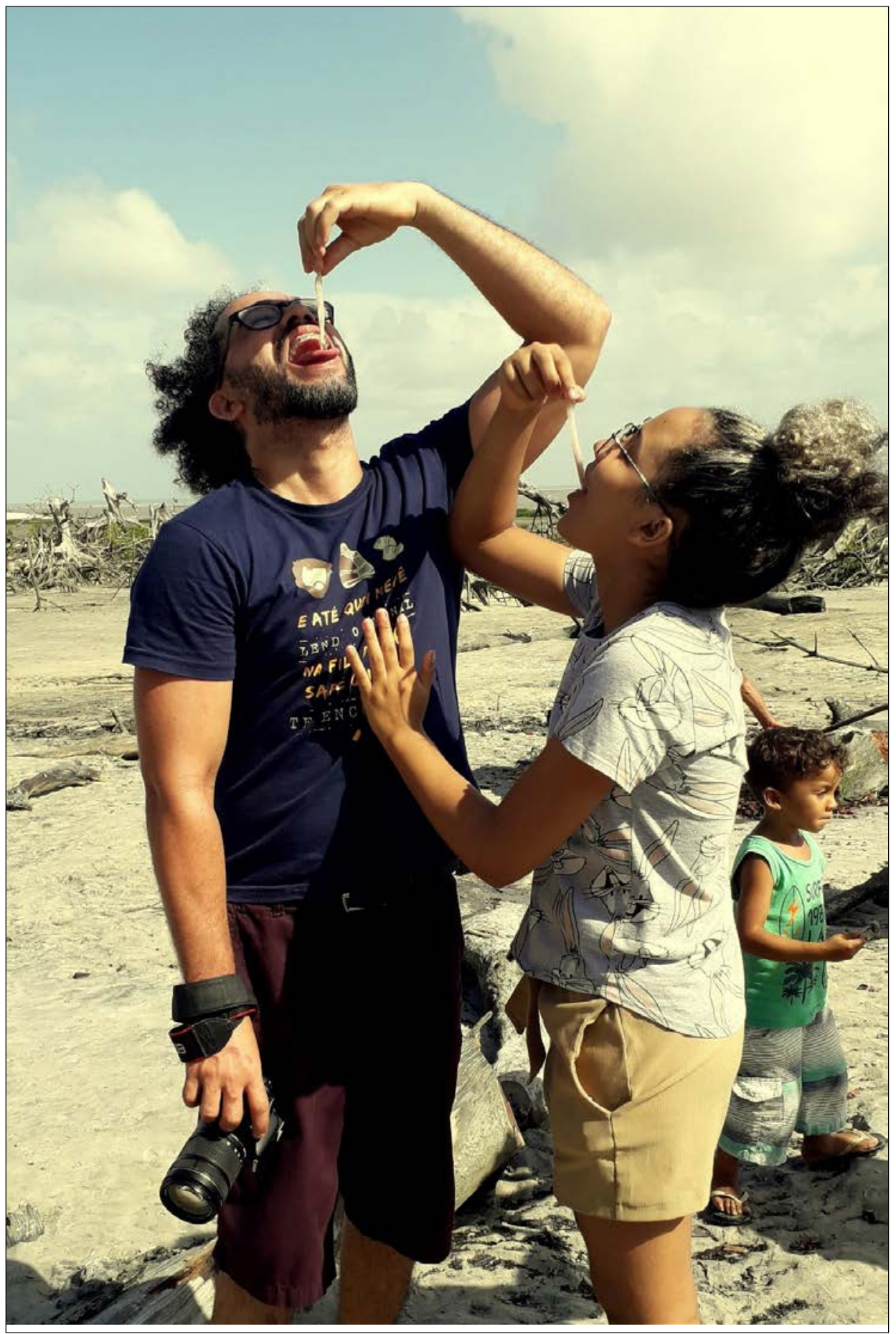

Figura 19 - Fernando e Amanda degustando turu. Foto: Alessandra Pinheiro da Costa (2019). 